\title{
OSTEÓLISE EXTENSA APÓS USO DE ÂNCORA BIOABSORVÍVEL: RELATO DE CASO E REVISÃO DA LITERATURA
}

\author{
EXTENSIVE OSTEOLYSIS AFTER THE USE OF A BIOABSORBABLE SUTURE \\ ANCHOR: CASE REPORT AND LITERATURE REVIEW
}

\author{
Fabio Farina Dal Molin
}

\section{RESUMO}

Os implantes bioabsorvíveis são usados com muita frequência no tratamento das lesões do manguito rotador e lesões labiais do ombro. Vários pesquisadores observaram áreas pequenas de osteólise depois da utilização destas âncoras bioabsorvíveis no tratamento das patologias do ombro. Teorias biológicas e mecânicas são levantadas para justificar a osteólise causada por estes materiais. É descrito o caso de um paciente que realizou, simultaneamente, sutura do manguito rotador com a técnica de dupla fileira e sutura da lesão de Bankart com âncoras bioabsorvíveis de PLDLA e fios Fiber Wire ${ }^{\circledR}$, evoluindo com extensa osteólise do colo anatômico do úmero. Tendo em vista que foi utilizada uma âncora na glenoide e esta não apresentou osteólise, levantase a hipótese de que os fatores mecânicos sejam importantes na etiologia desta complicação.

Descritores - Osteólise; Úmero; Implantes Bioabsorvíveis; Ombro

\section{INTRODUÇÃO}

Os implantes bioabsorvíveis são utilizados com muita frequência no tratamento das lesões do manguito rotador e lesões labiais do ombro. Foram desenvolvidos para permitir a fixação temporária do tecido, evitando as complicações dos implantes metálicos ${ }^{(1,2)}$, pois nos materiais bioabsorvíveis ocorre a desintegração do material após um período de tempo. A primeira geração de implantes era composta por ácido poliglicólico (PGA). Este apresentava uma grande reação tipo corpo estranho e absorção muito rápida ${ }^{(3,4)}$. A geração seguinte foi feita de ácido poly-L-lático (PLLA) e foi desenvolvida para ser degradada em um tempo muito maior ${ }^{(5,6)}$, apresen-

\section{ABSTRACT}

Bioabsorbable implants are frequently used in the treatment of rotator cuff and shoulder labrum injuries. Many authors have observed small areas of osteolysis after repair of shoulder abnormalities with absorbable anchors. Biological and mechanic theories are put forward to account for the osteolysis caused by these materials. We present a case of a patient who was simultaneously treated for a rotator cuff lesion with the double-row technique and a Bankart lesion with bioabsorbable PLLA anchors, and developed extensive osteolysis of the anatomic neck of the humerus. Because no lysis appeared in the glenoid around the other PLLA implant, we hypothesized that mechanical factors are important in the etiology of this complication.

Keywords - Osteolysis; Humerus; Bioabsorbable Implants; Shoulder

tando menos reações adversas ${ }^{(3)}$. Vários pesquisadores observaram áreas pequenas de osteólise depois da utilização destas âncoras bioabsorvíveis no tratamento das patologias do ombro. Teorias biológicas e mecânicas têm sido levantadas para justificar a osteólise causada por estes materiais ${ }^{(5,7-9)}$.

Levantamos a hipótese de que a causa da osteólise seja mecânica, pois, em nosso caso, não ocorreu lise na glenoide, na qual havia uma outra âncora bioabsorvível de PLDLA, e também não houve osteólise na âncora de PLDLA colocada no tubérculo maior lateralmente.

O objetivo deste trabalho é relatar o caso de um paciente que realizou, simultaneamente, sutura do mangui-

Mestre em Ortopedia e Traumatologia pela FCMSCSP; Ortopedista Especialista em Ombro e Cotovelo do Hospital Moinhos de Vento. 
to rotador com a técnica de dupla fileira e sutura da lesão de Bankart com âncoras bioabsorvíveis de PLDLA, evoluindo com extensa osteólise do úmero proximal.

\section{RELATO DE CASO}

Paciente masculino, 60 anos, apresentava queixa de dor em ombro direito havia um ano. Ao exame físico apresentava mobilidade normal, Neer + , Jobe + (com dor), força grau 5. No exame radiográfico apresentava acrômio tipo II e na ressonância nuclear magnética (RNM) evidenciava uma lesão do supraespinal de $2 \mathrm{~cm}$ com retração de $1 \mathrm{~cm}$. Foi submetido à videoartroscopia e na inspeção evidenciou uma lesão de Bankart, cicatrizada parcialmente com ausência de cartilagem na parte anteroinferior da glenoide em uma extensão de $5 \mathrm{~mm}$. O tendão do músculo supraespinal apresentava uma lesão de $2 \mathrm{~cm}$ de extensão, com retração de $1 \mathrm{~cm}$ e boa qualidade do tendão. Foi optado por cobrir a lesão de cartilagem, trazendo o lábio glenoideo sobre a erosão da superfície cartilaginosa e fixando com uma âncora de PLDLA(Biofastak ${ }^{\circledR}$ Arthrex Napple) e um ponto com fio Ethibond ${ }^{\circledR} 2$. No espaço subacromial foi feito acromioplastia e o tendão do supraespinal foi suturado com três âncoras de PLDLA (Bio-Corkscrew ${ }^{\circledR}$ Arthrex Napple). Duas foram posicionadas no colo anatômico do úmero, com dois fios Fiber Wire ${ }^{\circledR} 2$ cada, totalizando quatro pontos em U (matress). A terceira âncora foi colocada no tubérculo maior lateralmente e suturado o tendão com dois pontos simples, conforme a técnica de dupla fileira.

No pós-operatório, o paciente foi imobilizado com Velpeau, fazendo pendulares e rotação externa por seis semanas. Ele era bastante ativo e acabava mobilizando mais o braço do que o recomendado. Na quarta semana pósoperatória, quando começou a realizar mobilidade mais agressiva, iniciou com quadro de dor importante, evoluindo para capsulite adesiva. Foi tratado com 10 bloqueios do nervo supraescapular, apresentando melhora parcial, mas não satisfatória. Foi utilizado corticoide (meticorten $40 \mathrm{mg} /$ dia por 20 dias), com melhora durante o uso da medicação. O mesmo ocorreu com amitriptilina (25mg/dia). No $10^{\circ}$ mês pós-operatório, o paciente ainda queixavase de muita dor após trabalhar com o braço e limitação da amplitude de movimento (ADM). Ao exame físico, apresentava mobilidade diminuída (130, 0, L1); UCLA $21(6,6,4,5,0)$ e muita dor à mobilização. A radiografia (Figura 1) do ombro apresentava área de rarefação óssea no colo anatômico e tubérculo maior do úmero, compatível com o quadro de capsulite adesiva. Foi optado por fazer uma liberação capsular artroscópica.

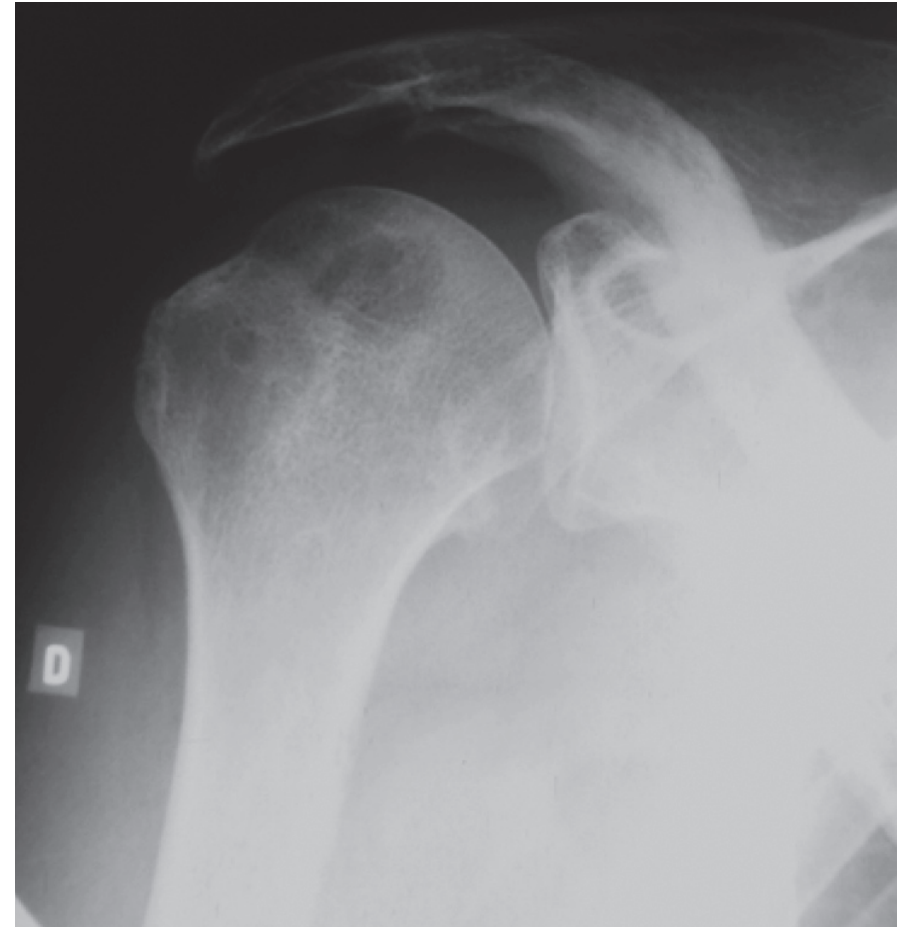

Figura 1 - Radiografia do ombro direito com imagem de rarefação óssea no colo anatômico do úmero.

O paciente foi submetido ao procedimento cirúrgico artroscópico e na inspeção percebeu-se dois orifícios de $1 \mathrm{~cm}$ de diâmetro nas âncoras mediais localizadas no colo anatômico (Figura 2). O tendão do supraespinal estava cicatrizado e o tendão do bíceps apresentava uma lesão degenerativa, pois estava em atrito com os

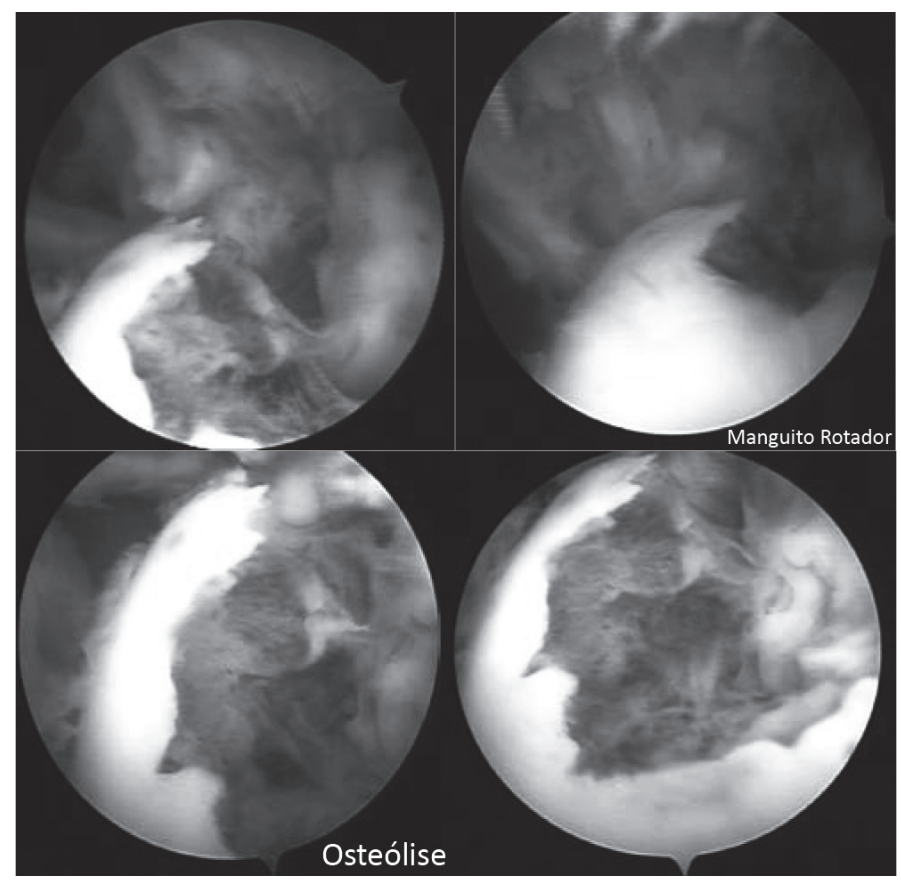

Figura 2 - Visualização interna da inserção do supraespinal no tubérculo maior, evidenciando extensa área de osteólise no local, com manguito rotador reinserido lateralmente à lesão. 
fios da âncora anterior, utilizada para sutura do supraespinal. Foram retirados os fios Fiber Wire ${ }^{\circledR}$ que se encontravam íntegros. $\mathrm{O}$ mesmo foi feito com as duas âncoras visíveis no colo anatômico do úmero, que estavam em processo de degradação. Foi realizada capsulotomia global com liberação do ombro congelado e realizada tenotomia do tendão do bíceps. O paciente ficou três dias internado com analgesia com ropivacaína
$2 \mathrm{mg} / \mathrm{ml}$ intra-articular contínua e fisioterapia três vezes por dia. Teve alta com mobilidade do ombro completa e indicação de fisioterapia passiva. O paciente evoluiu bem e hoje encontra-se com ADM normal, sem dor à mobilização do ombro e força muscular grau 5. Foi realizada uma tomografia computadorizada no pósoperatório, evidenciando extensa lesão lítica no colo anatômico do úmero (Figuras 3, 4 e 5).

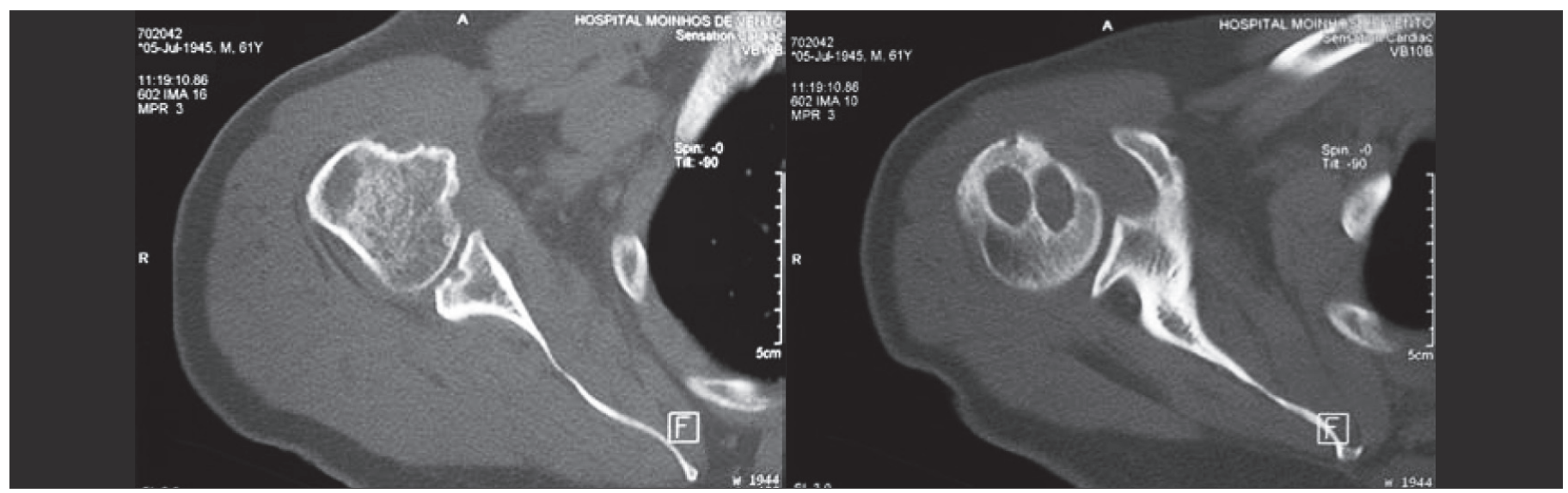

Figura 3 - TC com corte axial evidenciando cistos na cabeça do úmero.

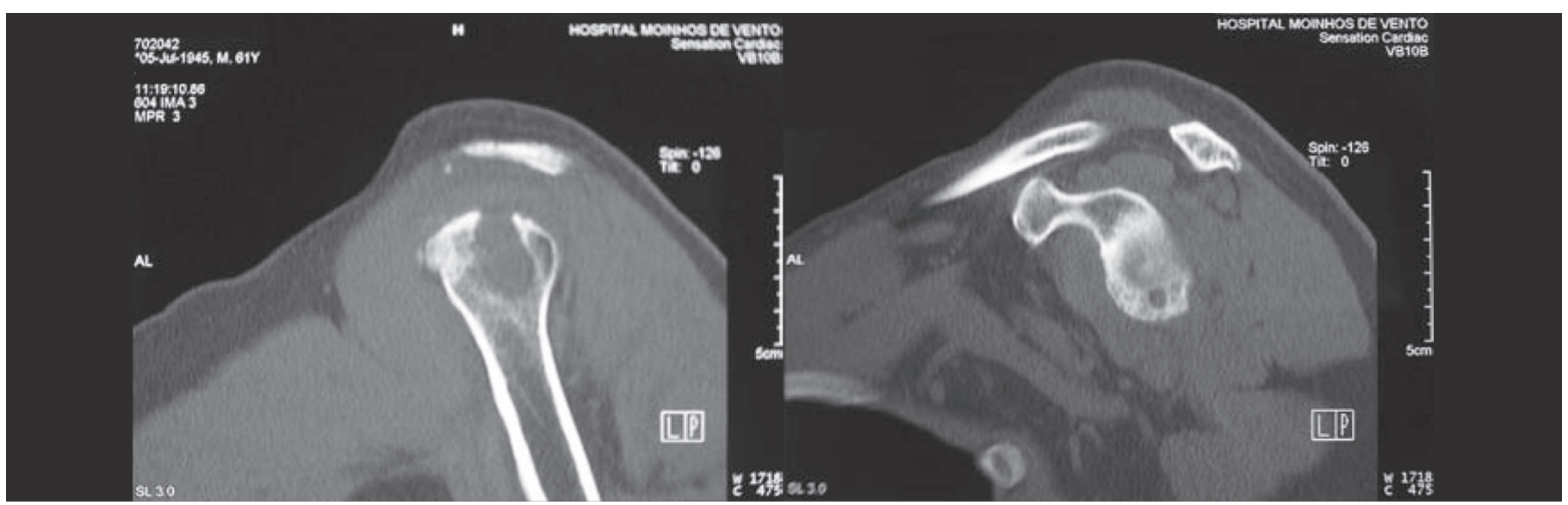

Figura 4 - TC com corte sagital com cisto na cabeça do úmero à esquerda e orifício da âncora na borda inferior da glenoide à direita.

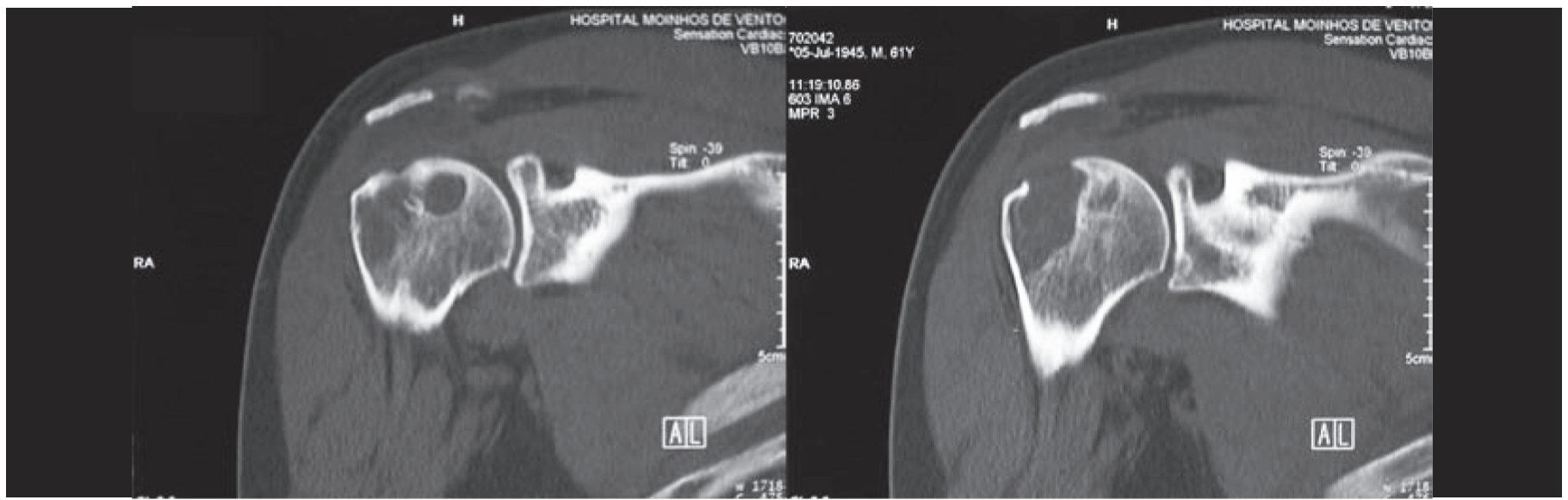

Figura 5 - TC com corte coronal evidenciando cistos no colo anatômico do úmero. 


\section{DISCUSSÃO}

O desenvolvimento dos materiais bioabsorvíveis para fixação de lesões no ombro surgiu para evitar as complicações causadas pelos implantes metálicos: a migração do implante para dentro da articulação, artrose secundária ${ }^{(1,2)}$. Todavia, há dúvidas sobre a potencialidade dos materiais bioabsorvíveis causarem sinovite. Os implantes com PGA estão associados à reação inflamatória clinicamente significativa ${ }^{(3)}$. Por outro lado, os implantes de PLLA têm mostrado biocompatibilidade em muitos estudos ${ }^{(10-12)}$. O mesmo ocorre com as âncoras bioabsorvíveis de copolímero, cujo estudo mostrou mínima resposta inflamatória histologicamente e não mostrou alterações inflamatórias ou císticas na $\mathrm{RNM}^{(13)}$.

Embora a maioria dos casos de reação inflamatória tenham sido relatados em casos que usaram implantes de PGA, Freehill et al ${ }^{(5)}$ encontraram uma porcentagem elevada de sinovite após o tratamento de lesões Bankart com âncoras de PLLA. Em uma coorte de 52 pacientes, em média oito meses após a cirurgia, 19\% dos casos desenvolveram sinovite sintomática. Nestes, foram encontradas múltiplas lesões líticas pequenas no local dos implantes.

Nosso caso descreve um paciente no qual foram usadas três âncoras PLDLA para fixar o manguito rotador com a técnica de dupla fileira, sendo que duas âncoras foram colocadas mediais, no colo anatômico, e uma foi colocada lateral ao tubérculo maior. Sabe-se que as forças do supraespinal são absorvidas pelas âncoras mediais e somente estas causaram lise. A âncora colocada no tubérculo maior não causou lise e esta não exerce função de sustentação. Concordamos com Glueck et $a l^{(9)}$ e acreditamos que a osteólise é determinada muito mais por fatores mecânicos que biológicos.

Este caso que relatamos apresenta semelhança com o caso de Glueck et $a l^{(9)}$ no qual foi utilizada uma âncora bioabsorvível para suturar uma lesão SLAP. No nosso paciente, utilizamos uma âncora na glenoide para cobrir uma lesão condral com o lábio inferior e corrigir uma lesão de Bankart. Este fato também contribui para a evidência dos fatores mecânicos como causa da osteólise, pois não houve nenhuma alteração lítica na glenoide.

Concluímos que este caso apresentado e a literatura pesquisada sugerem que a osteólise encontrada após a utilização de âncoras bioabsorvíveis PLLA parece não ter somente uma causa biológica. Possivelmente, uma causa mecânica seja responsável pela lise óssea que ocorre nestes pacientes. Estudos maiores com materiais bioabsorvíveis deverão esclarecer a verdadeira causa desta complicação.

\section{REFERÊNCIAS}

1. Ejnisman B, Andreoli CV, Pochini AC, Monteiro GC, Faloppa F, Cohen M. Artropatia glenoumeral pós-tratamento de lesões labiais com implantes metálicos. Rev Bras Ortop. 2006;41(5):167-72

2. Godinho GG, França FO, Freitas JMA, Aguiar PN, Leite MC. Complicações decorrentes do uso de âncoras metálicas em artroscopias de ombro. Rev Bras Ortop. 2009;44(2):143-7.

3. Böstman OM, Pihlajamäki HK. Adverse tissue reactions to bioabsorbable fixation devices. Clin Orthop Relat Res. 2000;(371):216-27.

4. Santavirta S, Konttinen $\mathrm{YT}$, Saito T, Gröndla M, Partio E, Kemppinen P, et al. Immune response to polyglycolic acid implants. J Bone Joint Surg Br. 1990;72(4):597-600.

5. Freehill MQ, Harms DJ, Huber SM, Atlihan D, Buss DD. Poly-L-lactic acid tack synovitis after arthroscopic stabilization of the shoulder. Am J Sports Med. 2003;31(5):643-7.

6. Peltoniemi H, Ashammakhi N, Kontio R, Waris T, Salo A, Lindqvist $\mathrm{C}$, et al. The use of bioabsorbable osteofixation devices in craniomaxillofacial surgery. Oral Surg Oral Med Oral Pathol Oral Radiol Endod. 2002;94(1):5-14.

7. Kartus J, Ejerhed L, Funck E, Kohler K, Sernert N, Karlsson J. Arthroscopic and open shoulder stabilization using absorbable implants: a clinical and radiographic com- parison of two methods. Knee Surg Sports Traumatol Arthrosc. 1998;6(3):181-8.

8. Warme WJ, Arciero RA, Savoie FH 3rd, Uhorchak JM, Walton M. Nonabsorbable versus absorbable suture anchors for open Bankart repair. A prospective, randomized comparison. Am J Sports Med. 1999;27(6):742-6.

9. Glueck D, Wilson TC, Johnson DL. Extensive osteolysis after rotator cuff repair with a bioabsorbable suture anchor: a case report. Am J Sports Med. 2005;33(5): 742-4

10. Ignatius A, Claes L. In vitro biocompatibility of bioresorbable polymers: poly(L,DLlactide) and poly(L-lactide-co-glycolide). Biomaterials. 1996;17(8):831-9.

11. Kaab MJ, Rahn BA, Weiler A, Curtis R, Perren SM, Schneider E. Osseous integration of poly-(L-co-D/L-lactide) $70 / 30$ and titanium suture anchors: an experimental study in sheep cancellous bone. Injury. 2002;33(Suppl 2):B37-42.

12. Muller M, Kaab MJ, Villiger C, Holzach P. Osteolysis after open shoulder stabilization using a new bioresorbable bone anchor: a prospective, non-randomized clinical trial. Injury. 2002;33(Suppl 2):B30-6.

13. Balch OK, Collier MA, DeBault LE, Johnson LL. Bioabsorbable suture anchor (co-polymer 85/15 D,L lactide/glycolide) implanted in bone: correlation of physical/mechanical properties, magnetic resonance imaging, and histological response. Arthroscopy. 1999;15(7):691-708. 